\title{
FEDERALIZAÇÃO DAS GRAVES VIOLAÇÕES AOS DIREITOS HUMANOS: MOTIVAÇÕES E ABRANGÊNCIA DO INSTITUTO ${ }^{1}$
}

\author{
Ana Luisa Zago de Moraes ${ }^{2}$ \\ Daniel Lena Marchiori Neto ${ }^{3}$
}

\begin{abstract}
RESUMO: Desde muito tempo, a preocupação com os direitos e garantias fundamentais orienta a comunidade internacional a exigir dos países o cumprimento dos tratados e convenções ratificados. No caso brasileiro, as incontáveis violações mostradas pela mídia levaram a uma postura mais efetiva, com vistas a recuperar o prestígio internacional. Nesse cenário, através da Emenda Constitucional n ${ }^{\circ} .45$, surge o Incidente de Deslocamento de Competência (IDC), um novo dispositivo processual que permite a federalização de processos que versarem sobre "grave violação aos direitos humanos". Contudo, os termos empregados pela Emenda são bastante genéricos, fato que certamente suscitará muitas dúvidas. Neste sentido, o presente artigo tem por escopo analisar o contexto em que a expressão direitos humanos é empregada, verificando sua precisão terminológica e algumas hipóteses de abrangência.
\end{abstract}

PALAVRAS-CHAVE: Direitos Humanos, Incidente de Deslocamento de Competência, Emenda Constitucional nº 45.

\section{Federalization of Grave violations of the Human Rights: motivations and extension of the institute}

\begin{abstract}
Since a long time, the preoccupation with the human rights guides the International Community to demand the accomplishment of the treaties and conventions ratified. In the Brazilian case, the numberless violations shown by the media caused a more effective reaction, seeking to recuperate the international reputation. In this panorama, the Incident of Jurisdictional Displacement arises through the Constitutional Amendment $n^{\circ}$. 45/2004; this new procedure instrument allows the federalization of lawsuits that deal with a "grave violation of the human rights". However, the terms used by the Amendment are very generic, fact that will certainly excite many doubts. Contemplating this, the present article aims to analyze the context in which the expression human rights is used, verifying its terminological precision and some examples.
\end{abstract}

KEY-WORDS: Human Rights, Incident of Jurisdictional Displacement, Constitutional Amendment n ${ }^{\circ} 45 / 2004$.

\footnotetext{
1 Artigo científico apresentado à Disciplina de Direitos Humanos e Democracia, do Departamento de Direito da Universidade Federal de Santa Maria, ministrada pelas Professoras Jânia Maria Lopes Saldanha e Ana Carolina Machado Ratkiewicz, como parte dos requisitos de avaliação.

${ }^{2}$ Acadêmica do Curso de Direito da Universidade Federal de Santa Maria.

${ }^{3}$ Acadêmico do Curso de Direito da Universidade Federal de Santa Maria.
} 


\section{Introdução}

Numa sociedade altamente globalizada e complexa, a preocupação com a efetividade dos direitos humanos transcende ao próprio limite físico dos Estados. Nesse sentido, a comunidade internacional, há décadas, vem exigindo o cumprimento dos tratados e convenções firmados, numa incessante preocupação com o indivíduo (visto talvez como um próprio sujeito de direito internacional) e suas garantias.

Para infortúnio de todos os brasileiros, o País tem sido palco de incontáveis violações aos direitos fundamentais, fatos que repercutem negativamente a imagem do Brasil perante os demais países. Desta forma, numa tentativa de recuperar o prestígio internacional, bem como de firmar a efetiva soberania sobre os crimes ocorridos em território pátrio, a Ementa Constitucional $\mathrm{n}^{\circ} .45$ instituiu um novo instrumento processual, o Incidente de Deslocamento de Competência (IDC).

Através desse dispositivo, poderá o Procurador-Geral da República solicitar, perante o Superior Tribunal de Justiça, o deslocamento da competência para a Justiça Federal quando a lide versar sobre grave violação aos direitos humanos. Contudo, desde as primeiras discussões, o IDC angariou inúmeras críticas, especialmente no que tange à esfera do pacto federativo e dos princípios do juiz e do promotor naturais. Além disso, a redação final do art. $109, \S 5^{\circ}$, da Constituição Federal é bastante confusa ao delimitar a abrangência do instituto às "graves violações aos direitos humanos". Afinal de contas, o que poderia ser considerado grave? E qual a extensão do termo direitos humanos?

Ressalta-se que o presente trabalho não tem por finalidade adentrar nas questões processuais e (in)constitucionais que a doutrina hodiernamente vem mencionando. O objetivo proposto é o de analisar o contexto em que o termo direitos humanos é empregado, verificando sua precisão terminológica e algumas hipóteses de abrangência, tendo como referencial teórico a visão do constitucionalismo moderno, em especial, de autores como Norberto Bobbio.

Para tanto, o artigo é dividido em quatro partes. Num primeiro momento, serão mostradas algumas das motivações que levaram à propositura do IDC. Logo após, far-se-á um breve histórico da tramitação do projeto, com ênfase nos trabalhos coordenados pela Dra. Flávia Piovesan. A terceira parte versa sobre o conceito e a força normativa dos direitos humanos. Por fim, tentar-se-á descrever um cenário para a interpretação desses direitos, conforme as premissas lançadas nas seções anteriores. 


\section{Motivações}

O Incidente de Deslocamento de Competência (IDC) foi instituído pela Emenda Constitucional $\mathrm{n}^{\circ} 45$, que acrescentou o inciso V-A e o parágrafo $5^{\circ}$ ao artigo 109 da Constituição Federal. Tal instituto sobreveio com o objetivo de garantir a efetiva aplicabilidade dos direitos humanos, em face do cumprimento de tratados internacionais ratificados pelo País.

Nesse passo, observa-se que os tratados são celebrados por pessoas jurídicas de Direito Internacional Público, vale dizer, os Estados soberanos e as organizações internacionais. Segundo Rezek (2005), em conformidade com o artigo 21, inciso I, da CF, cabe à União, e não aos Estados-Membros (pessoas jurídicas de direito público interno) dar efetividade aos acordos. Por isso, o deslocamento da competência para a Justiça Federal reproduz a intenção do Estado em resolver as violações de tais convenções. Trindade (2005) delineia com acuidade as obrigações dos Estados perante a comunidade internacional:

A supervisão internacional da compatibilidade dos atos internos dos Estado com suas obrigações internacionais de proteção; a compatibilização e prevenção de conflitos entre as jurisdições internacional e nacional em matéria de direitos humanos; a obrigação internacional dos Estados de provimento de recursos de direito interno eficazes; $e$ a função dos órgãos e procedimentos do direito público interno. (TRINDADE, 2005).

Cuida-se o IDC, portanto, de instrumento derivado da obrigação internacional dos Estados em prover-se de recursos de direito interno eficazes. Mesmo porque, ainda que não detivesse a jurisdição para processar e julgar os eventos violadores de tratados, a responsabilidade internacional decorrente lhes seria atribuída.

Sobreleva mencionar que no âmbito da Federação, o chamamento da União para viabilizar a tutela aos direitos humanos, quando os Estados não agirem adequadamente, já estava previsto na vigente ordem constitucional positiva, de acordo com o artigo 34, inciso VII, alínea b, da Constituição Federal, que prevê a intervenção Federal para assegurar os direitos da pessoa humana.

A motivação para o dispositivo do IDC reside no fato de que o Brasil aderiu aos principais tratados sobre Direitos Humanos e, ainda, à Corte Interamericana de Direitos Humanos em 1998. No mais, relatórios dessa Corte - criada em 1959 com o intuito de promover os direitos proclamados pela Declaração Americana dos Direitos e Deveres do Homem de 1948 e pela Declaração Universal dos Direitos Humanos de 1948 - constataram 
deficiências no direito interno e na atuação da Justiça dos países do continente americano, bem como instou os países a estabelecer recursos e procedimentos de direito interno para a plena vigência dos direitos humanos ${ }^{4}$.

Não obstante, repercussões midiáticas formaram o substrato para a construção da tese da federalização. Segundo Aras (2005), discutia-se a federalização do julgamento de crimes, como base na escalada de violência e da impunidade em várias regiões do país, cujos maiores exemplos são as chacinas e crimes de mando ocorridos em Eldorado dos Carajás (sendo este o evento que reacendeu os debates acerca do IDC), Vigário Geral, Carandiru, Parauapebas, Xapuri, Candelária e Queimados. Isso porque, além da grave violação aos direitos humanos, os mencionados eventos repercutem negativamente a imagem do Brasil perante o resto do mundo, ensejando uma resposta eficaz por parte da União.

Nesse sentido, Hélio Bicudo, vice-prefeito de São Paulo e ex-integrante da Comissão Interamericana dos Direitos Humanos (1998-2001), manifestou-se acerca do caso Eldorado de Carajás (homicídio de 19 trabalhadores rurais no conflito com a polícia militar do Estado do Pará, em 1996). Após discorrer sobre o cenário de impunidade, no qual formam-se quadrilhas de pistoleiros conjugadas com efetivos da polícia militar, responsáveis pela eliminação de importantes lideranças de movimentos populares, concluiu que:

A verdade é que os crimes contra os direitos humanos deveriam ser submetidos, desde sua apuração até o julgamento dos fatos, à Justiça Federal, isenta de injunções político-corporativas, como lamentavelmente ocorre na maioria dos Estados da Federação. [...] Assim se cumpriria o princípio de que os réus devem ser julgados por uma justiça autônoma e imparcial. (BICUDO apud SCREBER et al., 2005).

Preleciona Resek (2005) que, nas federações em geral, os crimes previstos em textos internacionais são delitos federais e da competência do sistema federal de justiça. Atribui, como vantagens, a jurisprudência uniforme, unida, sobre a temática, não tomando caminhos diversos conforme a unidade da federação em que o delito foi processado.

\footnotetext{
4 Nesse sentido, a resolução adotada na sétima sessão plenária, realizada em junho de 1997, ou seja, contemporânea às discussões sobre o Projeto de Emenda Constitucional, indica a adoção de mecanismo internos de promoção e proteção aos direitos humanos.
} 


\section{Histórico da tramitação do dispositivo}

O projeto inicial (PEC N. 368-A/96) foi de iniciativa do Poder Executivo e encaminhado por ocasião do lançamento do "Plano Nacional de Direitos Humanos" (PNDH) em 13 de maio de 1996, dispondo-se a acrescentar dois incisos ao art. 109 da Constituição Federal. Um deles determinava a competência originária da Justiça Federal para julgar "os crimes praticados em detrimento de bens ou interesses sob a tutela de órgão federal de proteção dos direitos humanos"; o outro dispunha sobre o deslocamento mediante provocação nos casos de "as causas civis ou criminais nas quais órgão federal de proteção dos direitos humanos ou o procurador-geral da República manifeste interesse". Segundo Screber et al. (2005):

A despeito do cuidado da Constituição em assegurar os Direitos Humanos, a realidade é que a violação desses direitos em nosso País tornou-se prática comum, criando um clima de revolta e de insegurança na população, além de provocar indignação internacional. É que o Estado brasileiro, ao cuidar de bem definir os ordenamentos que asseguram tais direitos descurou em relação a instrumentos capazes de assegurar o seu pleno exercício. De fato nenhuma mudança substancial foi estabelecida na competência e na organização das polícias pela Constituição de 1988. (SCREBER et al., 2005).

O presente projeto foi incorporado à PEC 96/92 (que dispunha sobre a Reforma do Poder Judiciário), tendo como relatora a Deputada Federal Zulaiê Cobra, acrescentando modificações significativas na redação, como a retirada da competência originária da Justiça Federal no caso dos crimes contra direitos humanos e a conseqüente inserção do $\S 5^{\circ}$ no art. 109, determinando a possibilidade do incidente de deslocamento de competência. A redação passou a ser a seguinte: "Nas hipóteses de grave violação de direitos humanos, o Ministério Público poderá suscitar, perante o Superior Tribunal de Justiça, incidente de deslocamento de competência para a Justiça Federal, na forma prevista na lei processual". Segundo Veloso et al. (2005), a justificativa que acompanhou o Projeto foi a seguinte:

A federalização dos crimes contra os direitos humanos é o instrumento que permite ao Poder Judiciário e ao Ministério Público Federal o processo e julgamento dos delitos que importem em violação de tratados, pelos quais a União responde na esfera internacional, no sentido de demonstrar interesse nacional na resolução destes casos. As graves violações aos direitos humanos são questões de interesse de todo o país, $e$ sua repercussão, interna e externa, extrapola os limites territoriais dos Estados da Federação. (VELOSO et al., 2005, p. 21). 
Na votação final da Câmara de Deputados, centrando a legitimidade ativa para postular o IDC no Procurador-Geral da República, bem como retirando o enunciado que a limitasse expressamente a eficácia do dispositivo à edição de lei, foi aprovada a seguinte redação em relação ao §5': "Nas hipóteses de grave violação de direitos humanos, o Procurador-Geral da República, com a finalidade de assegurar o cumprimento de obrigações decorrentes de tratados internacionais de direitos humanos dos quais o Brasil seja parte, poderá suscitar, perante o Superior Tribunal de Justiça, em qualquer fase do inquérito ou processo, incidente de deslocamento de competência para a Justiça Federal".

Durante os debates acerca do instituto, a Associação Nacional dos Procuradores da República, mediante comissão formada por integrantes do Grupo de Trabalho em Direitos Humanos, coordenado pela Procuradora Flávia Piovesan, definiu um rol de crimes aptos a ensejar o deslocamento de competência. Segundo Piovesan (2005), foram eles:

- tortura;

- homicídio doloso qualificado praticado por agente funcional de quaisquer dos entes federados;

- praticados contra as comunidades indígenas ou seus integrantes;

- homicídio doloso, quando motivado por preconceito de origem, raça, sexo, opção sexual, cor, religião, opinião política ou idade ou quando decorrente de conflitos fundiários de natureza coletiva;

- uso, intermediação e exploração de trabalho escravo ou de criança e adolescente em quaisquer das formas previstas em tratados internacionais.

Conforme a coordenadora dos trabalhos, embora se propusesse o deslocamento de competência exclusivamente em matérias criminais, mediante a adoção de rol taxativo de delitos, não destoou dos fundamentos anteriores. Além de reiterar a responsabilidade internacional da União em caso de violação dos tratados ratificados pelo Brasil, bem como ressaltar que a proposta está em consonância com a sistemática processual vigente, ressaltando a hipótese de "desaforamento" nos casos de crimes dolosos contra a vida, e também a intervenção federal, sobrelevou: 
A federalização dos crimes contra os direitos humanos é medida imperativa diante da crescente internacionalização dos direitos humanos, que, por conseqüência, aumenta extraordinariamente a responsabilidade da União nesta matéria. Se qualquer Estado Democrático pressupõe o respeito dos direitos humanos e requer a eficiente resposta estatal quando de sua violação, a proposta de federalização reflete sobretudo a esperança de que a justiça seja feita e os direitos humanos respeitados. (PIOVESAN, 2005).

No âmbito do Senado Federal, o Projeto recebeu o $n^{\circ} 29 / 2000$, cujo relator foi o Senador Bernardo Cabral. Acrescentou-se ao texto aprovado pela Câmara o inciso V-B, que dispunha sobre "os crimes praticados em detrimento de bens ou interesses sob tutela de órgão federal de proteção dos direitos humanos, nos termos da lei”, proposição esta que não obteve êxito, resultando o texto final nos termos encaminhados pela Câmara de Deputados.

Por conseguinte, na redação final, não foi consignada a expressão crimes, permanecendo o adjetivo grave e a ação nuclear violação em seu sentido lato, ou seja, não se limitando às agressões tipificadas penalmente. Com base na dual finalidade do dispositivo - de um lado, a responsabilização do Estado Brasileiro perante as Cortes Internacionais em decorrência do mau funcionamento dos recursos internos de prevenção e repressão nos mencionados casos, e de outro, o discurso da imparcialidade e a autonomia da Justiça Federal para os julgamentos em questão - é que emerge o IDC, ou seja, a possibilidade de o Procurador-Geral da República suscitar, perante o Superior Tribunal de Justiça, o incidente de deslocamento de competência para a Justiça Federal, na hipótese de grave violação aos direitos humanos.

\section{A problemática do conceito de Direitos Humanos}

Ao instituir o IDC, a redação da Emenda Constitucional n. 45 delimita sua abrangência apenas na hipótese de "grave violação aos direitos humanos". O legislador, entretanto, não procurou dar uma definição acerca do conteúdo da expressão direitos humanos, transferindo tal responsabilidade para a doutrina e a jurisprudência.

Não restam dúvidas de que esse ponto suscitará inúmeros debates. Como toda cláusula aberta, a redação do parágrafo $5^{\circ}$ do art. 109 permite um amplo grau de discricionariedade ao Procurador-Geral da República. Além do mais, sendo o instituto da federalização um 
instrumento fortemente político e midiático, há uma possibilidade muito grande de o IDC ser utilizado à revelia das garantias fundamentais do réu ${ }^{5}$.

Por isso, a busca de uma precisão conceitual torna-se de suma relevância para a compreensão do assunto. O artigo, evidentemente, não procura esgotar o tema, senão analisá-lo sob a ótica do constitucionalismo moderno.

Primeiramente, destaca-se que há uma pluralidade de expressões trazidas pela doutrina constitucionalista e internacionalista para designar os direitos humanos, de tal forma que parece impossível conceituá-los de forma precisa e inequívoca. Levando em consideração essa dificuldade, bem como a própria quantidade de teorias utilizadas para esse fim, que Bobbio (1992) chegou à conclusão de que "o problema fundamental em relação aos direitos do homem, hoje, não é tanto de justificá-los, mas o de protegê-los. Trata-se de um problema não filosófico, mas político" (p. 24).

Também defensor da tese de incompatibilidade de conceituação absoluta e inequívoca dos direitos humanos, Silva (1998) traz à tona a problemática de uma conceituação sintética e precisa dos mesmos. Essa celeuma cresce à medida que se empregam várias expressões para designá-los, tais como direitos naturais, direitos do homem, direitos individuais, direitos públicos subjetivos, liberdades fundamentais, liberdades públicas e direitos fundamentais do homem, dentre outras.

Além disso, muitas vezes, os doutrinadores supõem um aparente pleonasmo entre as expressões, como no caso de "direitos humanos" ou "direitos do homem", visto que a produção normativa é algo inerente à própria condição humana, sem ligação com particularidades determinadas. Por outro lado, como bem ressalta Comparato (2001), a questão pontual volta-se ao caráter de obrigatoriedade efetiva desses direitos no meio social.

Assim, o autor explica a distinção elaborada pela doutrina germânica em distinguir direitos humanos de direitos fundamentais. No primeiro caso, seriam os direitos imprescindíveis em geral, incluindo aqueles positivados no ordenamento ou não. Já os direitos fundamentais seriam justamente os que se encontram expressos nas legislações, tanto no plano interno quanto internacional. Há ainda uma outra classificação, que considera direitos fundamentais típicos e atípicos, sendo os últimos os ainda não declarados em textos normativos.

\footnotetext{
${ }^{5}$ A Associação Nacional dos Membros do Ministério Público (2005) divulgou uma moção de repúdio ao IDC, enumerando, dentre vários pontos, que a federalização viola os princípios do juiz e do promotor naturais, bem como o pacto federativo.
} 
Sarlet (2004) traz uma classificação diversa (mas não incompatível) com a de Comparato. Para o primeiro, há uma diferenciação entre os direitos humanos (estes positivados na esfera do direito internacional), os direitos do homem (no sentido de direitos naturais não, ou ainda não, positivados, cuja conotação lembra muito o jusnaturalismo), e os direitos fundamentais, como sendo os direitos reconhecidos ou outorgados e protegidos pelo direito constitucional interno de cada Estado. Nesse sentido:

A expressão "direitos humanos" guarda relação com os documentos de direito internacional, por referirem-se àquelas posições jurídicas que se reconhecem ao ser humano como tal, independentemente de sua vinculação com determinada ordem constitucional e que, portanto, aspiram à validade universal, para todos os povos $e$ tempos, de tal sorte que revelam um inequívoco caráter supranacional (internacional) (SARLET, 2004, p. 36).

Sarlet (2004) considera que, em torno da melhor terminologia a ser adotada, é de se destacar o uso da expressão "direitos humanos fundamentais". A razão deste termo é a de que a tese da distinção entre direitos humanos e direitos fundamentais peca pelo reducionismo e pela perda da unidade essencial e indissolúvel que há entre os direitos. Dentre os autores que compartilham dessa opinião, encontra-se José Afonso da Silva, como se pode observar abaixo:

\begin{abstract}
Direitos fundamentais do homem constitui a expressão mais adequada a este de estudo, porque, além de referir-se a princípios que resumem a concepção do mundo e informam a ideologia política de cada ordenamento jurídico, é reservada para designar, no nível do direito positivo, aquelas prerrogativas e instituições que ele concretiza em garantias de uma convivência digna, livre e igual de todas as pessoas. No qualificativo fundamentais acha-se a indicação de que se trata de situações jurídicas sem as quais a pessoa humana não se realiza, não convive e, às vezes, nem mesmo sobrevive; fundamentais do homem no sentido de que a todos, por igual, devem ser, não apenas formalmente reconhecidos, mas concreta e materialmente efetivados. (SILVA, 1998, p. 182).
\end{abstract}

No caso brasileiro, é possível observar uma certa preferência do legislador constituinte ao associar a expressão direitos humanos aos documentos de direito internacional. Tal assertiva extrai-se de uma análise teleológica do dispositivo - já que motivado na responsabilidade do Estado em dar efetividade ao mencionados acordos. Além disso, no julgamento do "Caso Dorothy Stang", primeiro incidente ajuizado, o Superior Tribunal de Justiça declarou ser requisito da causa de pedir a menção expressa do dispositivo específico do tratado que foi violado, a fim de fundamentar o pedido (IDC n. 1-0 - PA. Relator Ministro 
ARNALDO ESTEVES LIMA. Terceira Seção. Unânime. Data do julgamento: 8.6.2005. Ata da Publicação: 26/08/2005).

Há que se ressaltar também a não taxatividade do conceito. Embora o legislador expresse a necessidade de o Procurador-Geral da República indicar o dispositivo de tratado internacional, isso não significa, necessariamente, que a abrangência conceitual dos direitos humanos esteja vinculada ao Direito Internacional. Por uma leitura sistemática da Constituição, em especial do parágrafo segundo do art. $5^{\circ}$, verifica-se que o termo direitos humanos aparece implícito em várias ocasiões, mormente na expressão "direitos e garantias fundamentais", que pode ser tanto decorrente do regime e dos princípios adotados pela Carta Magna quanto de tratados internacionais. Nesse sentido, Tessler (2005), de forma bastante precisa, enuncia que "para a exata compreensão do que foi transferido à Justiça Federal e então tentar traçar limites ao disposto na nova disposição encartada no artigo 109 da CF/88 com redação dada pela EC45, há de se ter como sinônimos as expressões direitos humanos e direitos fundamentais, na esteira da melhor doutrina".

Em que pese a classificação doutrinária, não se pode perder o norte de considerar o caráter fundamental e histórico desses direitos. Segundo Bobbio (1992, p. 6), “os direitos não nascem todos de uma vez. Nascem quando devem ou podem nascer. Nascem quando o aumento do poder do homem sobre o homem [...] cria novas ameaças à liberdade do indivíduo ou permite novos remédios para as suas indulgências". Por conseguinte, "os direitos do homem constituem uma classe variável, como a história destes últimos séculos demonstra suficientemente" (p. 18).

Nesse sentido, a Inglaterra teve importância ímpar na produção de cartas e estatutos assecuratórios de direitos fundamentais. Inicialmente, o fulcro desses direitos era o de limitar o arbítrio estatal frente ao indivíduo. Como exemplos, têm-se a Magna Carta (1215-1225), a Petition of Rights (1628), o Habeas Corpus Amendment Act (1679) e o Bill of Rights (1688).

A Declaração Francesa de 1789, por sua vez, calcada em uma rigorosa concepção individualista, é de certa forma semelhante ao contrário das declarações das ex-colônias Inglesas na América, embora com um caráter mais universalizante. É tido como o documento caracterizador do Estado Liberal, que serviu de modelo às declarações constitucionais de direitos dos séculos passados.

Percebe-se que, num primeiro momento, os direitos humanos são resultado da necessidade de limitação e controle dos abusos de poder do próprio Estado e de suas 
autoridades constituídas, visando ao pleno desenvolvimento da personalidade humana. São, pois, direitos negativos, no sentido de impedir uma determinada ação estatal. Esta nova visão de pensar o Direito (através de um rol de garantias mínimas) consagrou importantes princípios, quase sempre positivados nas Constituições, como a dignidade humana, a igualdade e a legalidade. Os direitos fundamentais, neste ponto, são antecedentes ao próprio surgimento do constitucionalismo. Este último, "tão-somente consagrou a necessidade de insculpir um rol mínimo de direitos humanos em um documento escrito, derivado diretamente da soberana vontade popular". (MORAES, 2000, p. 19).

O pensamento cristão e a concepção dos direitos naturais foram, para a teoria francesa, os principais motivadores das declarações de direitos. Todavia, sendo fundada basicamente na concepção restrita de liberdades públicas, não atina com a necessidade de envolver nessa problemática os direitos econômicos, sociais e culturais, aos quais se denominam brevemente direitos sociais.

Nesta seara, a Constituição Mexicana de 1917 representou o primeiro avanço na consolidação de uma nova geração de direitos, agora não mais negativos, mas sim positivos, ou seja, que necessitam da intervenção do Estado. Segundo Comparato (2001, p. 174), "a Carta Política mexicana de 1917 foi a primeira a atribuir aos direitos trabalhistas a qualidade de direitos fundamentais, juntamente com as liberdades individuais e os direitos políticos".

Posteriormente, a Constituição de Weimar, em 1919, seguiu na mesma linha da Carta mexicana, bem como das convenções da OIT e da Conferência de Washington no mesmo ano. Por outro lado, a Carta Alemã (Weimarer Verfassung) foi mais abrangente, garantindo, além dos direitos trabalhistas e previdenciários, o direito fundamental à educação, saúde, nãodiscriminação em virtude de gênero, entre outros.

Essa disposição histórica dos direitos permite classificá-los em gerações. Parte da doutrina classifica os direitos fundamentais em direitos de primeira, segunda e terceira gerações, baseando-se na ordem histórico-cronológica em que passaram a ser constitucionalmente reconhecidos. Como bem ressalta Celso de Mello,

enquanto os direitos de primeira geração (direitos civis e políticos) - que compreendem as liberdades clássicas, negativas ou formais - realçam o princípio da liberdade e os direitos de segunda geração (direitos econômicos, sociais e culturais) - que se identificam com as liberdades positivas, reais ou concretas - acentuam o princípio da igualdade, os direitos de terceira geração, que materializam poderes de titularidade coletiva atribuídos genericamente a todas as formações sociais, consagram o 
princípio da solidariedade e constituem um momento importante no processo de desenvolvimento, expansão e reconhecimento dos direitos humanos, caracterizados, enquanto valores fundamentais indisponiveis, pela nota de uma essencial inexauribilidade (STF - Pleno - MS n 22164/SP - rel. Min. Celso de Mello, Diário de Justiça, Seção I, nov. 1995, p. 39.206). (Celso de Mello apud MORAES 2000, p. 44).

Interessante é a objetividade de Ferreira Filho (1995) ao expor, metaforicamente, que a primeira geração engloba os direitos de liberdade; a segunda, os direitos de igualdade e a terceira, por conseguinte, complementa o lema da Revolução Francesa: liberdade, igualdade, fraternidade.

Bobbio (1992), por sua vez, classifica os direitos em quatro gerações. A primeira seria formada pelos direitos civis, notavelmente os direitos à vida, à liberdade, à propriedade e à igualdade perante a lei. Incluem-se também o direito ao devido processo legal (due process of law), o habeas corpus, o direito de petição, a liberdade de imprensa, de expressão, de associação, entre outros. Para o autor, tais direitos nascem contra o Estado, visto que surgem para impedir ou limitar a ação estatal.

Os direitos de segunda geração corresponderiam aos direitos políticos, em especial o direito ao voto e a capacidade eleitoral passiva, revelando uma conexão entre os direitos humanos e a democracia. Nascem como direitos de participar do Estado. Justamente como a primeira geração, são também negativos, visto que delimitam uma zona de não-intervenção estatal.

A terceira geração é compreendida pelos direitos econômicos, sociais de culturais. Distinguem-se das etapas anteriores pelo caráter intervencionista. Agora não mais se exige uma mera omissão estatal, mas uma ação positiva. Para Bobbio (1992), são direitos a partir ou pelo Estado, como os direitos à assistência social, à saúde, à educação, ao trabalho, etc.

A quarta e última dimensão corresponde aos direitos de solidariedade e de fraternidade. O destinatário aqui não é mais o Estado, senão o próprio gênero humano, razão suprema de uma existencialidade. Bonavides apud Sarlet (2004) enumera alguns exemplos, como o direito à paz, à autodeterminação dos povos, ao desenvolvimento, ao meio ambiente e qualidade de vida, bem como o direito à conservação e utilização do patrimônio histórico e cultural e o direito de comunicação. Bobbio (1992) os denomina direitos para além do Estado.

Ressalta-se que alguns autores, como Lafer (1991), já indicam a existência de uma quinta ou até mesmo sexta geração de direitos. Todavia, as classificações não importam uma divisão dos direitos. Pelo contrário, as conquistas históricas representadas pelas gerações não 
se excluem, mas se complementam. Segundo Moraes (2000), a interdependência demonstra que as várias previsões constitucionais, embora autônomas, possuem diversas intersecções para atingirem suas finalidades. A complementariedade, por seu turno, sinaliza que os direitos humanos fundamentais não devem ser interpretados isoladamente, mas sim de forma conjunta com a finalidade de alcance dos objetivos previstos pelo legislador constituinte.

As categorias de direitos não são, portanto, compartimentos jurídicos estanques, absolutos e excludentes. São, sim, instrumentos didáticos doutrinariamente criados a fim de tentar demonstrar, da melhor maneira possível, a correspondência da criação e evolução dos direitos fundamentais com os respectivos momentos históricos que impulsionaram o surgimento dos mesmos.

\section{Abrangência do IDC}

Um desafio muito grande que a doutrina e a jurisprudência terão pela frente será o de resolver a lacuna deixada pelo legislador quanto à abrangência do IDC. É certo que se trata de violações graves aos direitos humanos, mas o significado de "grave" e "direitos humanos" ainda suscitará muitas dúvidas. Segundo Maluly (2005), em tese apresentada ao III Congresso do Ministério Público de São Paulo, "os parâmetros estabelecidos na Constituição Federal para a incidência da chamada "federalização da competência" são insuficientes e, para evitar a banalização de sua adoção, é imprescindível que se sujeite ao princípio constitucional da proporcionalidade (adequação, necessidade e proporcionalidade em sentido estrito)".

O presente artigo, nesta parte, não procurou delinear maiores comentários acerca do adjetivo grave. Tentar-se-á, na medida do possível, descrever um cenário para a interpretação da expressão "direitos humanos", conforme as premissas lançadas na seção anterior.

Inicialmente, ressalta-se que as infrações penais, sem dúvida alguma, serão o objeto primordial apto a ensejar o IDC. Afinal de contas, as graves violações aos direitos humanos configuram, em tese, significativas lesões a bens jurídicos tutelados pelo ordenamento jurídico brasileiro, ensejadoras de reprimenda por parte do Estado-Acusador-Juiz. Embora o histórico da tramitação do projeto que instituiu o IDC demonstrou uma certa intenção do legislador em limitar o instituto às causas criminais, a redação final não o fez, permitindo uma interpretação extensiva. Nesse sentido, Tessler (2005) afirma que "se tratam de causas gerais, não só causas criminais, e não é a prima ratio". 
Exemplificativamente, na seara penal, tem-se o delito de tortura, tipificado pelo art. $1^{\circ}$ da Lei 9.455/1997, no cotejo com a Convenção Interamericana contra a Tortura concluída em Cartagena (1985), bem como o crime de genocídio, criminalizado pelo art. $1^{\circ}$ da Lei 2.889/1956, em face do Pacto Internacional dos Direitos Civis e Políticos e também da Convenção Americana. No mais, certamente os delitos de exploração sexual de crianças e adolescentes, quer seja o de tráfico internacional de pessoas (art. 231 do Código Penal) quer seja o de favorecimento à prostituição (art. 228 do Código Penal), quando em detrimento de diversas vítimas na faixa etária delineada pelo Estatuto da Criança e do Adolescente - que define ser criança o indivíduo até completar 12 anos de idade, e adolescente até completar 18 -, ensejarão o deslocamento, com fundamento na Convenção de Nova York sobre os Direitos da Criança (1990).

Ainda em matéria criminal, dever-se-á atentar aos direitos e garantias fundamentais do réu, tais como o de ser submetido ao julgamento pelo Tribunal do Júri (mesmo após o deslocamento para a Justiça Federal) no caso de crime doloso contra a vida, da vedação aos tribunais de exceção, da duração razoável do processo, dos limites da eventual prisão processual, dentre outras extraídas do artigo $5^{\circ}$ da Constituição Federal. E, não obstante a adjetivação "grave", deve-se atentar à minimização de pré-julgamentos, mormente os influenciados pela mídia, que, segundo Zaffaroni (2003), é um dos principais agentes criminalizadores em face da garantia fundamental da presunção de inocência.

Não se pode olvidar, outrossim, que não se limita o IDC às matérias criminais. A força normativa da expressão direitos humanos deve ser lida em toda a sua completude, não taxativamente, sob pena de anacronismo com relação ao avanço histórico da consolidação dos direitos fundamentais, bem como da própria leitura sistemática da Constituição.

Nesse sentido, o ressarcimento relativo os danos decorrentes de graves violações a direitos trabalhistas (pertencentes aos direitos sociais, classificados como de segunda ou terceira geração), tais como o trabalho escravo (sem prejuízo ao julgamento do delito correspondente, de competência originária da Justiça Estadual), bem como preconceitos de raça ou sexo, também ensejariam o deslocamento de competência para a Justiça Federal. Contudo, aqui exsurge um problema de ordem processual que merecerá um grande apreço. Pensando na disposição das competências pela CF, verifica-se que a Justiça do Trabalho é uma justiça especializada da União, não dos Estados-Membros. Assim sendo, é possível pensar que não há razões para haver o deslocamento da competência nas questões trabalhistas, visto que 
Justiça Laboral é de responsabilidade da União e, conseqüentemente, o dever de dar cumprimento aos acordos internacionais por esse sujeito estaria sendo cumprido. $\mathrm{O}$ deslocamento, portanto, careceria de interesse de agir por parte do propositor, em que pese a eventual inefetividade desta. O mesmo poderia se pensar nos casos de competência da Justiça Militar da União.

Todavia, sem querer adentrar nessa questão processual, pode-se pensar também o inverso. Embora a Justiça do Trabalho e até a Militar serem patrocinadas pela União, é somente a Justiça Federal que julga as lides em que ela figura como parte. Por isso, é muito difícil pensar que os julgamentos nos foros laborais e militares correspondam de fato a um julgamento de cuja responsabilidade a União tomaria para si, visto a própria conjuntura da Justiça Federal. Mas essa questão os autores deixam em aberto para um debate futuro.

Outra matéria que provavelmente comportará deslocamento de competência é a do direito ambiental, inclusive quando da discussão acerca da responsabilidade por danos ambientais materiais e morais. Elencado no rol dos direitos de terceira, quarta ou até mesmo quinta geração, a defesa do meio ambiente deixou de ser uma questão privada, adquirindo status constitucional. O art. 225 da Carta Magna, seguindo as diretrizes da Conferência das Nações Unidas de Estocolmo (1972) e da Declaração do Rio (1992), considerou que "todos têm direito ao meio ambiente ecologicamente equilibrado, bem de uso comum do povo e essencial à sadia qualidade de vida, impondo-se ao Poder Público e à coletividade o dever de defendê-lo e preservá-lo para as presentes e futuras gerações".

O meio ambiente é um patrimônio da humanidade, uma própria extensão do direito à vida, visto ser muito difícil imaginar uma vida digna fora de um meio ambiente equilibrado e sadio. Impõem-se ao Poder Público o dever de protegê-lo. Desta forma, tendo em vista os inúmeros tratados ratificados pelo Brasil, Antunes (2005) ressalta que uma das consequiências do IDC é justamente a "provocação do Procurador Geral da República (4) [sic], a federalização de todas as questões ambientais graves, visto que a nova redação do artigo 109 da Lei Fundamental da República, ampliou a competência da Justiça Federal para acrescentar às suas tradicionais competências aquela de julgar causas referentes a direitos humanos".

\section{Considerações Finais}

O Incidente de Deslocamento de Competência, embora não imune de críticas quanto à sua estrutura e viabilidade constitucional, representa uma preocupação dos Poderes Públicos 
com o efetivo cumprimento dos direitos e garantias fundamentais do cidadão. Lamenta-se apenas que a adoção do instituto tenha sido dada não por uma reflexão prévia acerca do sistema de competência do Poder Judiciário, mas sim como uma resposta midiática aos escândalos vivenciados pelo País.

De qualquer forma, o IDC está em vigor pela Emenda Constitucional $\mathrm{n}^{\circ}$. 45, já tendo sido proferida jurisprudência a respeito - como no caso Dorothy Stang. As lacunas possivelmente deixadas pelo legislador deverão, a partir de agora, ser objeto de discussão, tanto por parte dos doutrinadores quanto pelos tribunais.

Dentre os pontos polêmicos, encontra-se a questão da abrangência do art. $109, \S 5^{\circ}$, da CF. Pelo dispositivo, o Procurador-Geral da República pode solicitar o deslocamento de competência para a Justiça Federal dos processos em que haja uma suposta violação grave aos direitos humanos. Por outro lado, a ambigüidade e a vagueza do dispositivo é algo bastante preocupante, na medida em que o IDC possa vir a ser simplesmente banalizado - sem contar o risco de as próprias garantias processuais do réu serem desconsideradas.

Nesse sentido, a primeira conclusão do trabalho é de que a expressão "direitos humanos" não deve ser limitada ou ter sua força normativa restringida pelas inúmeras classificações que a doutrina constitucionalista e internacionalista elencam, como "direitos do homem", “direitos fundamentais", etc. Todos esses vocábulos devem ser tidos como sinônimos, sob pena de redução da unidade essencial e indissolúvel que há entre os direitos. Seria lamentável que uma separação meramente acadêmica entre os termos implicasse uma perda qualitativa do conteúdo simbólico que os direitos possuem.

Quanto às hipóteses de abrangência, parece evidente que o deslocamento não está reduzido às causas criminais. Embora tenha havido uma certa predisposição nesse sentido, durante as discussões do projeto, a redação final do art. 109 manteve o sistema de cláusula aberta. Por causa disso, as violações referidas não se limitam às mencionadas matérias, mas a qualquer assunto referente a direitos humanos que tenha sido ratificado pelo Brasil em tratados internacionais, incluindo, a título de exemplo, questões ambientais, civilistas, trabalhistas, de direitos das crianças e adolescentes, dentre outras.

Portanto, é imperioso que a expressão direitos humanos seja analisada extensivamente, sob pena de comprometer o avanço histórico da consolidação dos direitos fundamentais através de suas gerações. O Incidente de Deslocamento de Competência, nessa evolução, deve ser visto como um dos instrumentos destinados a conferir efetividade a tão amplos direitos. 


\section{Referências Bibliográficas}

ANTUNES, Paulo de Bessa. Meio ambiente e Direitos Humanos. In: DANNEMANN Siemsen Meio Ambiente Consultores. São Paulo: 2005. Disponível em: < http://www.dannemann.com.br/site.cfm?app=show $\& d s p=p b a 32 \& p o s=5.15 \& \operatorname{lng}=p t>$. Acesso em: 31 out. 2005.

ARAS, Vladimir. Federalização dos crimes contra os direitos humanos. Jus Navigandi, Teresina, ano 9, n. 687, 23 mai. 2005. Disponível em:

<http://jus2.uol.com.br/doutrina/imprimir.asp?id=6762>. Acesso em: 31 out. 2005.

ASSOCIAÇÃO NACIONAL DOS MEMBROS DO MINISTÉRIO PÚBLICO. CONAMP Associação Nacional dos Membros do Ministério Público. Brasília: 2005. Disponível em: < http://www.conamp.org.br/>. Acesso em: 12 nov. 2005.

BOBBIO, Norberto. A Era dos Direitos. Rio de Janeiro: Campos, 1992.

COMPARATO, Fábio Konder. A afirmação histórica dos direitos humanos. 2. ed. São Paulo: Saraiva, 2001.

FERREIRA FILHO, Manoel Gonçalves. Direitos humanos fundamentais. São Paulo: Saraiva, 1995.

LAFER, Celso. A Reconstrução dos Direitos Humanos. São Paulo: Companhia das Letras, 1991.

MALULY, Jorge Assaf. A Federalização da competência para julgamento dos crimes praticados contra os direitos humanos. In: MINISTÉRIO Público de São Paulo. São Paulo: 2005. Disponível em: <http://www.mp.sp.gov.br/congresso/3congressomp1dia.htm>. Acesso em: 15 dez. 2005.

MORAES, Alexandre de. Direitos humanos fundamentais: teoria geral, comentários aos arts. $1^{\circ}$ a $5^{\circ}$ da Constituição da República Federativa do Brasil, doutrina e jurisprudência. $3^{\text {a }}$ ed. São Paulo: Atlas, 2000.

MORAIS, José Luis Bolzan de. Do Direito social aos interesses transindividuais: o Estado e o Direito na ordem contemporânea. Porto Alegre: Livraria do Advogado, 1996. 
PIOVESAN, Flávia. Direitos Humanos Internacionais e Jurisdição Supra-nacional: A exigência de federalização. In: REDE Direitos Humanos e Cultura. São Paulo: 2005. Disponível em: < http://www.dhnet.org.br/inedex.htm>. Acesso em: 31 out. 2005.

PIOVESAN, Flávia. Direitos Humanos e o Direito Constituicional Internacional. São Paulo: Max Limonad, 2002.

RESEK, Francisco. Direito Internacional Público. 10ª ed. São Paulo: Saraiva, 2005.

SARLET, Ingo Wolfgang. A eficácia dos Direitos Fundamentais. $5^{a}$ ed. Porto Alegre: Livraria do Advogado, 2004.

SILVA, José Afonso da. Curso de Direito Constitucional Positivo. $15^{\text {a }}$ ed. São Paulo: Malheiros, 1998.

SCREBER, Simone; CASTRO E COSTA, Flavio Dino. Federalização da competência para o julgamento de crimes contra os direitos humanos. In: ASSOCIAÇÃ̃O dos Juízes Federais do Brasil. Brasília: 2005. Disponível em: < http://www.ajufe.org.br/index.php?ID_MATERIA=389>. Acesso em: 06 nov. 2005.

TESSLER, Marga Inge Barth. Competências judiciárias estabelecidas pela Emenda Constitucional 45 de 31-12-2004: reforma do judiciário. In: TRIBUNAL Regional Federal da $4^{\mathrm{a}} \quad$ Região. Porto Alegre: 2005. Disponível em: < http://www.trf4.gov.br/trf4/upload/arquivos/curriculo_juizes/competencias_judiciarias_estabelecidas_pela_ec_45.pdf>. Acesso em: 15 dez. 2005.

TRINDADE, Antonio Augusto Cançado. Direito Internacional e Direito Interno: sua Inteiração na proteção dos Direitos Humanos. In: REDE Direitos Humanos e Cultura. São Paulo: 2005. Disponível em: < http://www.dhnet.org.br/inedex.htm>. Acesso em: 31 out. 2005.

VELOSO, Zeno; GUSTAVO, Vaz Salgado (Orgs.). Reforma do Judiciário Comentada. São Paulo: Saraiva, 2005.

ZAFFARONI, Eugenio Raúl; BATISTA, Nilo. Direito Penal Brasileiro: teoria geral do Direito Penal. Rio de Janeiro: Revan. 2003. 